\title{
Molecular Weight and Solubility Studies of Some Novel Polyaniline Induced by Montmorillonite clay Called Maghnite- $\mathrm{H}^{+}$ (Algerian MMT)
}

\author{
Rahmouni Abdelkader*, Harrane Amine, Belbachir Mohammed \\ Département of chemistry, laboratory of polymer chemistry Faculty of sciences, Oran university, \\ BP 1524.El M'nouar 31000 Oran. Alegeria \\ *Corresponding author E-mail: ramaek23@yahoo.fr
}

\begin{abstract}
Aniline is well known to be polymerized by protonic acid such as chlorhydric acid $(\mathrm{HCl})$. The cationic polymerization of ANI was examined in the presence of $\mathrm{Mag}-\mathrm{H}^{+}$(eco-catalyst layered) powder in bulk at $0^{\circ} \mathrm{C}$. In this paper, polyaniline (PANI)/ $/ \mathrm{Na}^{+}$-maghnite (Mag) clay nanocomposite materials have been successfully prepared for the heterogeneous polymerization of aniline. The prepared samples were subsequently characterized by FTIR spectroscopy, 1H-NMR spectroscopy and gel permeation chromatography (GPC). It should be noted that the nanocomposite coating containing $1 \mathrm{wt} . \%, 3 \mathrm{wt} . \%$, and $5 \mathrm{wt}$. \% of clay loading was found to exhibit an observable structure, physicochemical properties and controlled molecular weight. Oxidation states of PANI were found to influence the gel content molecular weight distribution, solubilite and conductivity of homopolymer produced, conformation and configuration of the polymer molecules.
\end{abstract}

Keywords: Polyaniline; GPC; 1 H-NMR spectroscopy; Maghnite- $H^{+}$, Molecular weight, solubility, conductivity.

\section{Introduction}

One of the most studied pairs in conducting polymer/layered inorganic solid nanocomposite are the nanocomposites composed of polyaniline (PANI) chains confined in the galleries of layered silicates with the unique characteristics mentioned above[1]. After the observation of PANI intercalation into $\mathrm{Na}^{+}$-exchanged silicates[2] a number of studies on the preparation, properties and applications of PANI/layered silicate anocomposites were carried out [3]. Most recently [4] Yang and Chen reported the synthesis of PANI/clay nanocomposites and found that more PANI chains are formed between interlayer spacings of the modified clay.

In particular, the class of organic materials known as inherently conducting polymers has been investigated for electronic device applications [5] and even though these materials have great promise, many scientific and technological issues have not been sufficiently addressed or understood [6]. Unlike materials consisting of small molecules, the properties of polymers are extremely dependent on the conformation and configuration of the polymer molecules [7].

Smectite clays are a popular layered material for the preparation of polymer clay materials in the past decade [8], because of its small particle and easy of intercalation [9]. The MMT, whose lamella is constructed from an octahedral alumina sheet sandwiched between two tetrahedral silica sheets, exhibits a net negative charge on the surface of layers [10].

Montmorillonite have both Bronsted and Lewis acid sites and when exchanged with cations having a high charge density, as protons, produce highly active catalysts for acid-catalysed reactions [11]. It have been demonstrated that intercalated organic molecules on the surface of Montmorillonite are mobile and can be highly polarize when situated in the space between the charged clay layers $[12,13]$. The present study examines the catalytic activity of Algerian proton exchanged montmorillonite clay $\left(\right.$ Maghnite- $\left.\mathrm{H}^{+}\right)$. It was demonstrated that there is an excellent correlation between the acid treatment and the catalytic activity of Maghnite [14]. 


\section{Experimental}

\subsection{Materials and method}

Aniline 99\%, potassium persulphate $98 \%$ (Aldrich), hydrochloric acid (35\%-38\%),MMT clay was obtained from ENOF Maghnia (Algeria). The MMT- $\mathrm{H}^{+}\left(\mathrm{Mag}-\mathrm{H}^{+}\right)$was prepared as described by Belbachir and al [15], and water $(\mathrm{PH}<7)$ were used to synthesis éméraldine salt $\left(\mathrm{PANI}-\mathrm{Mag}-\mathrm{H}^{+}\right)$by emulsion polymerization. Some of the emeraldine base (PANI-EB), non-conducting form of polyaniline, was prepared by de-protonating PANI-ES in NaOH Solution $(0.5 \mathrm{M})$. A doping EB was carried out in aqueous medium of hydrochloric acid ( $\mathrm{HCl})$ [16].

Maghnite- $\mathrm{H}^{+}$was prepared according to the process reported in our previous study [17]. Raw-Maghnite (20g) was crushed for $20 \mathrm{mn}$ using a prolabo ceramic balls grinder. It was then dried for $2 \mathrm{~h}$ at $105^{\circ} \mathrm{c}$. The Maghnite was placed in an Erlenmeyer flask together with $500 \mathrm{ml}$ of distilled water. The Maghnite/water mixture was stirred using a magnetic stirrer and combined with $0.25 \mathrm{M}$ sulfuric acid solution, until neutralization was achieved over 2 days at room temperature, the mineral was then washed with distilled water to become sulfate free and then dried at $105^{\circ} \mathrm{C}$.

The present study provide process for preparing polyaniline or another polymer conductors such as ( polypyrole , plythiophene ) or substituted polyaniline ( o-anisidine , o-methoxy-aniline , o-toluidine ......), which comprises dissolving oxidizing agent (solid) slowly in mixture of catalyst and monomer ( $\mathrm{Mag}-\mathrm{H}^{+}$, aniline ) after $30 \mathrm{mn}$ at ranging temperature $\left(0^{\circ} \mathrm{C}\right.$ to $\left.4^{\circ} \mathrm{C}\right)$ and during $10 \mathrm{mn}$, after this time we added drop by drop $15 \mathrm{ml}$ to $20 \mathrm{ml}$ of water, the reaction mixture was stirred for $1 \mathrm{~h} 30 \mathrm{mn}$ at the optimal conditions. At the end of polymerization, we obtained the emeraldine salt /clay (PANI-ES / Mag- $\mathrm{H}^{+}$). Whereas, the Mag-H it's separate by filtration because it's insoluble in the solvents in which the polymer is soluble. Eventually, the result it's black solution ( polymer-solvent ), after evaporation result a black powder it's ( PANI-ES), washed several times with water and methanol, where dried at $60^{\circ} \mathrm{c}$ for $48 \mathrm{~h}$ for characterization .

The polyaniline base (PANI-EB) was obtained by deal treatment of polyaniline salt (PANI-ES) with an solution of dilute $\mathrm{NaOH}(0.5 \mathrm{M})$. A doping EB was carried out in aqueous medium of hydrochloric acid (1M). Approximately $1,5 \mathrm{~g}$ of fine powder of polyaniline base was suspended in $200 \mathrm{~mL}$ of appropriate acid solution. After stirring at room temperature for $5 \mathrm{~h}$, the black polymer salt was collected by filtration followed by drying under dynamic vacuum for 48 $\mathrm{h}$ at $60^{\circ} \mathrm{C}$.

$5.1 \mathrm{ml}$ of $(0.055 \mathrm{~mol})$ aniline was added to $6 \%$ of $(0.306 \mathrm{~g}) \mathrm{Mag}-\mathrm{H}$ clay catalyst layered. The reaction was stirring for $30 \mathrm{mn}$ at $0^{\circ} \mathrm{c}$, after this time $3 \mathrm{~g}$ of $(0,013 \mathrm{~mol}) \mathrm{K}_{2} \mathrm{~S}_{2} \mathrm{O}_{8}$ was added slowly during $10 \mathrm{mn}$, after this we added drop by drop $15 \mathrm{ml}$ of water. The reaction was continued for $1 \mathrm{~h} 30 \mathrm{mn}$ in the optimal condition $\left(0^{\circ} \mathrm{C}\right)$.

The precipitate product was filtered and washed with distilled water as far as neutralization, because this product contained traces of initiator, oligomer and monomer. In the end, we obtained black solid which be composed of (polymer-montmorillonite). Whereas, the Mag-H it's separate by filtration because it's insoluble in the solvents in which the polymer is soluble. Eventually, the result it's black solution ( polymer-solvent ), after evaporation result a black powder it's ( PANI-ES ), washed several times with water and methanol, where dried at $60^{\circ} \mathrm{c}$ for $48 \mathrm{~h}$ for characterization .

$5.1 \mathrm{ml}$ of $(0,055 \mathrm{~mol})$ aniline was added to $5 \%$ of ( $0.275 \mathrm{~g}) \mathrm{Mag}-\mathrm{H}$ clay catalyst layered. The reaction was stirring for $30 \mathrm{mn}$ at $0^{\circ} \mathrm{c}$, after this time $3 \mathrm{~g}$ of $\mathrm{K}_{2} \mathrm{Cr}_{2} \mathrm{O}_{7}$ was added slowly during $10 \mathrm{mn}$, after this we added drop by drop $15 \mathrm{ml}$ of water. The reaction was continued for $1 \mathrm{~h} 30 \mathrm{mn}$ in the optimal condition $\left(0^{\circ} \mathrm{C}\right)$.

The precipitate product was filtered and washed with distilled water as far as neutralization, because this product contained traces of initiator, oligomer and monomer. In the end, we obtained black solid which be composed of (polymer-montmorillonite). Whereas, the Mag-H it's separate by filtration because it's insoluble in the solvents in which the polymer is soluble. Eventually, the result it's black solution (polymer-solvent), after evaporation result a black powder it's (PANI-ES ), washed several times with water and methanol, where dried at $60^{\circ} \mathrm{C}$ for $48 \mathrm{~h}$ for characterization .

$5.1 \mathrm{ml}$ of $(0.055 \mathrm{~mol})$ aniline was added to $2 \%$ of $(0.102 \mathrm{~g}) \mathrm{Mag}-\mathrm{H}$ clay catalyst layered. The reaction was stirring for $30 \mathrm{mn}$ at $0^{\circ} \mathrm{c}$, after this time $3 \mathrm{~g}$ of $(0,022 \mathrm{~mol}) \mathrm{CuCl}_{2}$ was added slowly during $10 \mathrm{mn}$, after this we added drop by drop $15 \mathrm{ml}$ of water. The reaction was continued for $1 \mathrm{~h} 30 \mathrm{mn}$ in the optimal condition $\left(0^{\circ} \mathrm{C}\right)$.

The precipitate product was filtered and washed with distilled water as far as neutralization, because this product contained traces of initiator, oligomer and monomer. In the end, we obtained black solid which be composed of (polymer-montmorillonite). Whereas, the Mag-H it's separate by filtration because it's insoluble in the solvents in which the polymer is soluble. Eventually, the result it's black solution ( polymer-solvent ), after evaporation result a black powder it's ( PANI-ES ), washed several times with water and methanol, where dried at $60^{\circ} \mathrm{C}$ for $48 \mathrm{~h}$ for characterization . 


\subsection{Measurements}

${ }^{1} \mathrm{H}$ nuclear magnetic resonance (NMR) measurements were carried out on a $300 \mathrm{MHz}$ Bruker NMR Spectrometer equipped with a probe BB05 mm, in CDCl3. Tetramethylsilane (TMS) was used as the internal standard in these cases. Fourier transform infrared spectroscopy (FTIR) spectra were obtained between 900 and $4000 \mathrm{~cm}^{-1}$ on an ATI Matson FTIR No 9501165. Ten scans were averaged at a resolution of $4 \mathrm{~cm}^{-1}$ for the solid tested samples of modified and unmodified montmorillonite prepared as $\mathrm{KBr}$ pellets (ca. $3 \%$ by mass in $\mathrm{KBr}$ ).

Fourier transform infrared spectroscopy (FTIR) spectra were obtained between 900 and $4000 \mathrm{~cm}-1$ on an ATI Mattson FTIR no. 9501165. Ten scans were averaged at a resolution of $4 \mathrm{~cm}-1$ for the solid tested samples of modified and unmodified montmorillonite prepared as $\mathrm{KBr}$ pellets (ca. $3 \%$ by mass in $\mathrm{KBr}$ ).

DSC measurements were carried out on a TA instrument, according to the following program: the specimens were first heated from ambient temperature to $250{ }^{\circ} \mathrm{C}$ at $10{ }^{\circ} \mathrm{C} / \mathrm{min}$ maintained at this temperature during 5 minutes then cooled to $25^{\circ} \mathrm{C}$ at $20^{\circ} \mathrm{C} / \mathrm{min}$. The tests were performed on a TA instrument (TGA Q500) by heating the samples from 20 to $550{ }^{\circ} \mathrm{C}$ at $20{ }^{\circ} \mathrm{C} / \mathrm{min}$. DTG thermograms giving the variations of the weight loss derivative as a function of temperature.

Viscosity measurements were carried out with an Ubbelhode Capillary Viscosimeter (viscologic TI1, version 3-1 Semantec). Intrinsic viscosity [ $\eta]$, was measured at $30^{\circ} \mathrm{C}$ in benzene.

GPC measurements of the samples were carried out using a WISP 712, Waters Associates chromatograph, THF was used as solvent and the instrument was calibrated to a first approximation with polystyrene of known molecular weights.

The flow rate of tetrahydrofuran was $10 \mathrm{ml} / \mathrm{min}$. intrinsic viscosity measurements were performed on SEMATECH Viscologic TI 1 apparatus at $25^{\circ} \mathrm{C}$ using THF as solvent.

The purification of polymers were carried out by dissolving the product in chloroform $\left(\mathrm{CDCl}_{3}\right)$ and filtering to eliminate the Mag-H+. Then, chloroform was removed by evaporation.

\section{Results and discussion}

\subsection{Polymerization and characterizations of product}

\subsubsection{Experiments conditions and results}

The results of polymerization of aniline $(0.055 \mathrm{~mol})$ induced by $6 \%$ ( ) of Maghnite-H+ $0.25 \mathrm{M}$ is reported in Table 1 .

Table.1: Polymerization of Aniline induced by Maghnite- $\mathrm{H}^{+} 25 \mathrm{M}$ at $0^{\circ} \mathrm{C}$.

\begin{tabular}{|l|l|l|l|l|l|l|l|}
\hline Experiment & $\begin{array}{l}\text { Mag-H+ } \\
(\%)\end{array}$ & $\begin{array}{l}\text { Time } \\
(\mathbf{h})\end{array}$ & $\begin{array}{l}\text { Yield } \\
(\boldsymbol{\%})\end{array}$ & Mn & Mw & Polydispersity & $\begin{array}{l}\text { number of repetitive } \\
\text { units }\end{array}$ \\
\hline 1 & 10 & 3 & 61.58 & $3.540,00$ & $7.825,00$ & 2,21 & 38,47 \\
\hline 2 & 6 & 3 & 84.23 & $12.210,00$ & $17.652,00$ & 1,44 & 132,71 \\
\hline 3 & 2 & 3 & 69.81 & 548,00 & 913,00 & 1,66 & 5.95 \\
\hline
\end{tabular}

\subsubsection{Characterization spectroscopic of products}

For FTIR polyaniline Fig.1, the literature data indicated that the characteristic absorption peaks are assigned to the $\mathrm{C}-\mathrm{H}$ aspect bending vibration on the replaced benzene ring at $832 \mathrm{~cm}^{-1}$ and the $\mathrm{C}-\mathrm{N}$ bond stretching vibrations at $1308 \mathrm{~cm}^{-1}$. 1498 and $1590 \mathrm{~cm}^{-1}$ represent the absorption peaks of benzene- and quinine-type in polyaniline chain [18].

The product (obtained by room temperature reaction in 3 days) which was reduced with 100 ml of hydrazine solution (20\%) displays two groups of signals in the 1H-NMR spectra Fig.2. The down field signals centered at $7.2 \mathrm{ppm}$ are due to four aromatic protons of the pure reduced form (leucoemeraldine base). Integral ratio of the NH proton signal appeared at $3.55 \mathrm{ppm}$. Whereas non-reduced form of the product (Emeraldine base) gave a ${ }^{1} \mathrm{H}-\mathrm{NMR}$ spectra with slight shift of the peak positions (i.e. NH protons appear at $4.81 \mathrm{ppm}$ and aromatic protons centered at $7.3 \mathrm{ppm}$ ) [19]. 


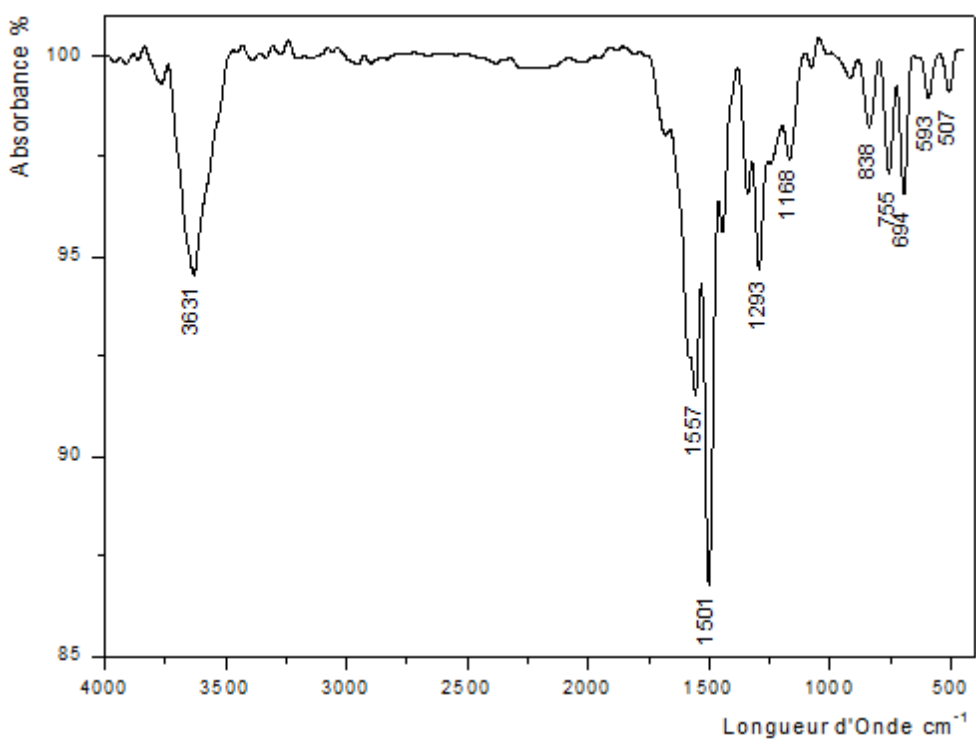

Fig 1: FT-IR spectra of the polymer (PANI-ES) obtained by the intercaled method between Aniline and Maghnite (black powder) at $0^{\circ} \mathrm{C}$.

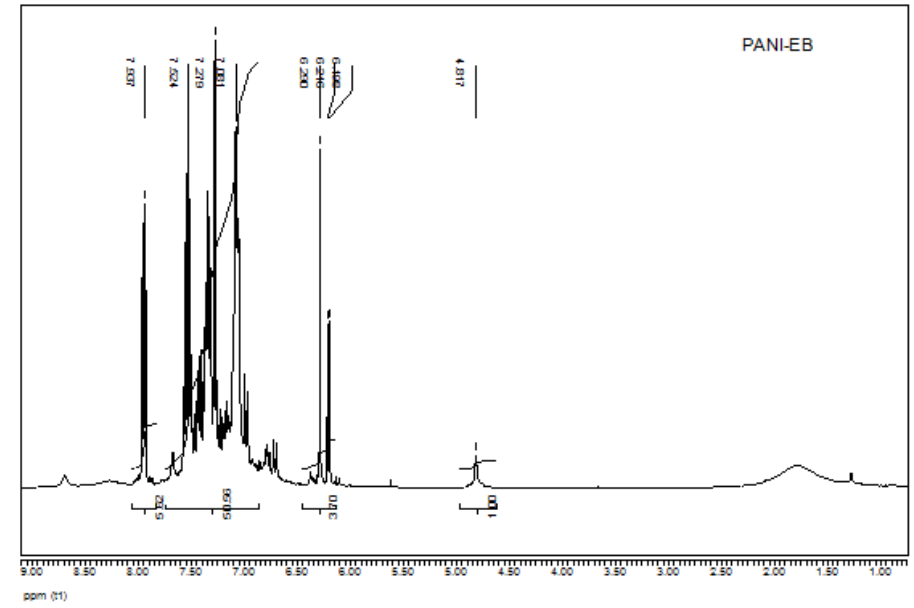

Fig 2: 1H NMR spectrum (300 MHz, CDCl3, Tetramethylsilane (TMS) was used as the internal standard) of polyaniline-Maghnite (PANI-EB) obtained by the polymerization of aniline with $\mathrm{Mag}-\mathrm{H}+$ initiator system in $\mathrm{CDCl} 3$ at $0^{\circ} \mathrm{C}$.

\subsection{Effect of molecular weight on solubility and conductivity of polyaniline salt}

By UV-vis spectra, on taking the soluble PANI in various solvents, we can calculate the band of energy by this equation.

$$
\Delta \mathbf{E}=\mathbf{h v}=\mathbf{h} \mathbf{c} / \lambda
$$

The solubility parameter $(\boldsymbol{\delta})$ is usually expressed in $\left(\mathrm{cal} / \mathrm{cm}^{3}\right)^{1 / 2}$ or preferably $\left(\mathrm{j} / \mathrm{cm}^{3}\right)^{1 / 2}$ units for many compound is defined from Hildebrand- Scotchard Solution theory is : $\boldsymbol{\delta}=(\Delta \mathbf{E} / \mathbf{V})^{1 / 2}$

The electrical conductivity of materials was measured by the four-point method. Four points aligned and spaced the same distance are applied by simple pressure on the sample. A current I is injected through the outer tips with a current source, thus creating a potential variation. Voltage $U$ can be measured between two points connected to internal voltmeter [20-21].

$\rho=\mathrm{R}\left(\pi \cdot \mathrm{r}^{2} / \mathrm{e}\right)(\Omega \cdot \mathrm{cm})$

$\sigma=1 / \rho(\mathrm{S} / \mathrm{cm})$ 
The measured value of the transverse strength of the polyaniline is converted to volume resistivity, using equation (1), and then the electrical conductivity is calculated from the equation (2). The value of electrical conductivity $(\sigma)$ and parameter of solubility $(\delta)$ are presented in the following Table.2.

Table.2: Properties physicals and chemicals of polyaniline salt pillet $(1 \mu)$ with different molecular weight.

\begin{tabular}{|l|l|l|l|}
\hline Samples & $\mathrm{PANI}-\mathrm{CDCl}_{3} \mathrm{wt} \%$ & $\sigma(\mathrm{S} / \mathrm{cm}) 25^{\circ} \mathrm{C}$ & $\delta\left(\mathrm{j} / \mathrm{cm}^{3}\right)^{1 / 2} 25^{\circ} \mathrm{C}$ \\
\hline \multirow{4}{*}{ Low molecular weight } & 10 & 7.83 & 1.04 \\
\cline { 2 - 4 } & 50 & 12.09 & 0.98 \\
\cline { 2 - 4 } & 100 & 14.17 & 0.96 \\
\hline \multirow{3}{*}{ Intermediate molecular weight } & 10 & 12.63 & 0.87 \\
\cline { 2 - 4 } & 50 & 28.16 & 0.84 \\
\cline { 2 - 4 } & 100 & 35.26 & 0.80 \\
\hline \multirow{3}{*}{ High molecular weight } & 10 & 25.70 & 0.72 \\
\cline { 2 - 4 } & 50 & 46.82 & 0.61 \\
\cline { 2 - 4 } & 100 & 83.15 & 0.56 \\
\hline
\end{tabular}

\subsection{Effect of solvent in solubility and molecular weight of polyaniline salt (PANI-ES)}

Effect of solvent in solubility and molecular weight of polyaniline salt (PANI-ES) composite was determined in a number of organic solvents Table.3. The PANI-ES composite in powder form was added to $100 \mathrm{~mL}$ of each solvent including: Dimethylformamide, Acetonitrile, toluene, dichloromethane, THF, and chloroform and stirred for $1 \mathrm{~h}$ before filtering. The dry weight of the filter paper was used to calculate the solubility and molecular weight of the PANI-ES composite. It was found that, PANI-ES composite is relatively soluble in all above mentioned solvents [22] .The best solvents for PANI-ES composite are determined to be Dimethylformamide and Toluene. So we can conclude that: the solubility, the conductivity and the molecular weight increases with the polarity and concentration of solvents[23].

Table.3: Effect of solvent in solubility and molecular weight of polyaniline salt

\begin{tabular}{|l|l|l|l|}
\hline Solvants & Solubilité $(\mathbf{g} / \mathbf{1 0 0 m})$ & \multicolumn{1}{|c|}{ Molecular Wight } \\
\cline { 2 - 4 } & & \multicolumn{1}{c|}{ Mn } & Mw \\
\hline Dimethylformamide & 0.55 & $23.000,00$ & 29150,00 \\
Toluène & 0.54 & 17062,00 & 21537,00 \\
Chloroforme & 0.49 & 12367,00 & 18952,00 \\
Dichloromethane & 0.38 & $8.000,00$ & 10468,00 \\
Acétonitrile & 0.22 & $5.451,00$ & 7032,00 \\
Tétrahydrofurane & 0.14 & $3.121,00$ & $4.903,00$ \\
\hline
\end{tabular}

\subsection{GPC characterization}

Polyaniline salt form (PANI-ES) was synthesized by potential-time profiling the chemical oxidative polymerization of aniline, using $\mathrm{K}_{2} \mathrm{~S}_{2} \mathrm{O}_{8}$ as oxidant, Maghnite-H+ as an catalyst and quenching the reaction in solution of chloroforme $\mathrm{CDCl}_{3}$.

Fig. 3 show a GPC (gel permeation chromatograph) of polyaniline in the salt form dissolved in 50\% chloroform and the vertical axis is the ultraviolet detector response and the horizontal axis is the peak retention time in minutes. Two peaks are evident in Fig. 1, first in retention time $(21.262 \mathrm{mn})$ in region $(6,01 \%)$ which corresponds to a weight average molecular weight of approximately $\left(\mathrm{Mn}=644,00 \mathrm{~g} / \mathrm{mol}^{-1}, \mathrm{Mw}=746,00 \mathrm{~g} / \mathrm{mol}^{-1}\right)$ of polyaniline salt form (PANIES) and peak at $(22,435 \mathrm{mn})$ in the region $(93,99 \%)$ correspond to a weight average molecular weight approximately $\left(\mathrm{Mn}=33,00 \mathrm{~g} / \mathrm{mol}^{-1}, \mathrm{Mw}=114,00 \mathrm{~g} / \mathrm{mol}^{-1}\right.$ ) of monomer (Aniline) and oligomers.

Table 4:GPC of PANI-ES composite in THF

\begin{tabular}{|l|l|l|l|l|l|l|l|}
\hline & Sample Name & RT & Area & \% Area & Mn & Mw & Polydispersity \\
\hline 1 & PANI-ES & 17.973 & 1318425 & 6.01 & 644 & 746 & 1.158385 \\
\hline 2 & PANI-ES & 23.638 & 20616395 & 93.99 & 33 & 52,00 & 3.413146 \\
\hline
\end{tabular}




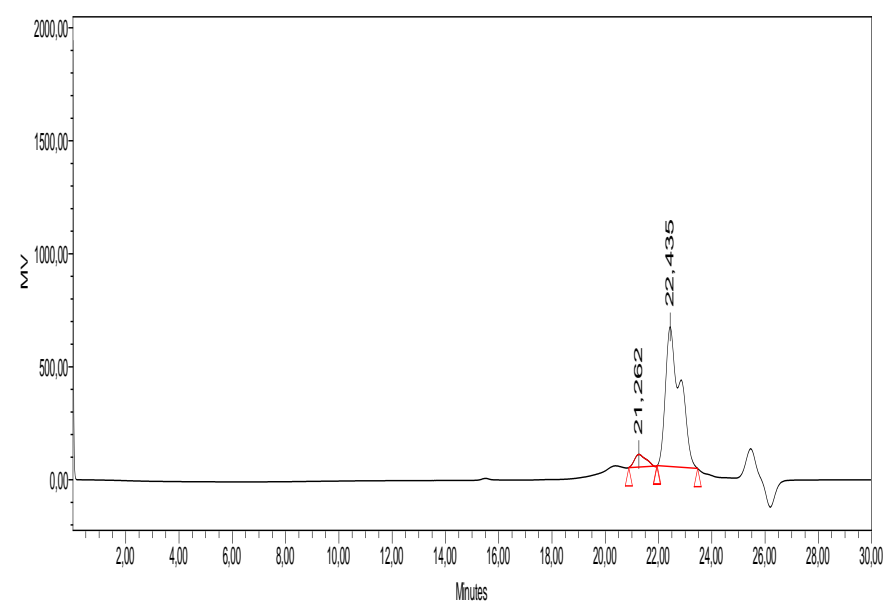

Fig.3: GPC chromatogram of PANI-ES with $6 \% \mathrm{Mag}^{-\mathrm{H}^{+}}$at $0^{\circ} \mathrm{C}$ for $1 \mathrm{~h} 30 \mathrm{mn}$, Polydispersity $=1.15$.

If the reaction mixture was poured into aqueous $\mathrm{NaOH} 0.5 \mathrm{M}$, a precipitate of analytically pure emeraldine base (PANIEB) was obtained [24]. Gel permeation chromatograph indicated another two peaks, first in the retention time $(20,838 \mathrm{mn})$ which corresponds to a weight average molecular weight of approximately $\left(\mathrm{Mn}=815,00 \mathrm{~g} / \mathrm{mol}^{-1}\right.$, $\mathrm{Mw}=1002,00 \mathrm{~g} / \mathrm{mol}^{-1}$ of polyaniline base form (PANI-EB) and peak at $(22,033 \mathrm{mn})$ correspond to a weight average molecular weight approximately $\left(\mathrm{Mn}=29,00 \mathrm{~g} / \mathrm{mol}^{-1}, \mathrm{Mw}=136,00 \mathrm{~g} / \mathrm{mol}^{-1}\right)$ of monomer (Aniline) and oligomers. Fig.4 show GPC chromatogram of polyaniline base (PANI-EB).

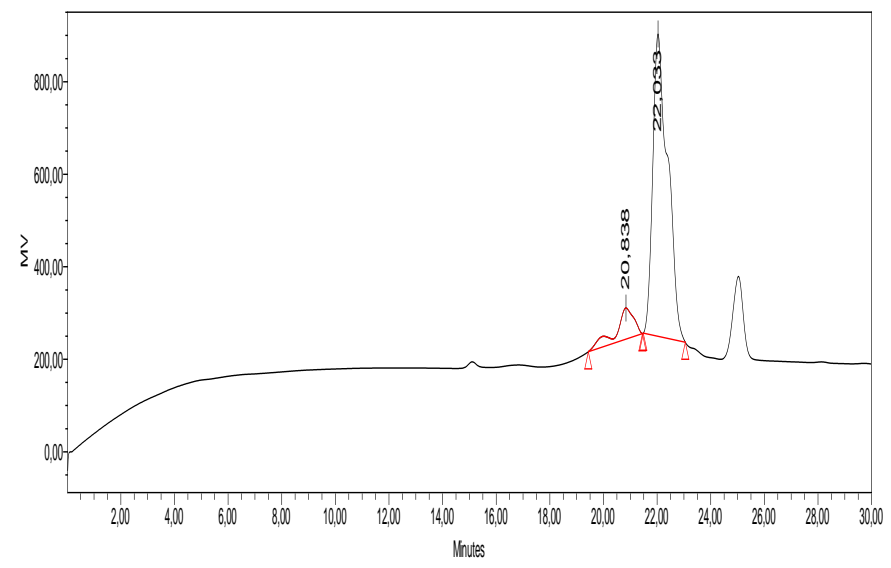

Fig.4: GPC chromatogram of PANI-EB with $6 \% \mathrm{Mag}-\mathrm{H}$ at $0^{\circ} \mathrm{C}$ for $1 \mathrm{~h} 30 \mathrm{mn}$

It is known that the GPC analysis of the synthesized polyaniline emeraldine salt (PANI-ES) and emeraldine base (PANI-EB) in NMP solution has a bimodal molecular weight distribution [25]. In our study solvant it's chloroform $\left(\mathrm{CDCl}_{3}\right.$, another GPC chromatogram indicated a bimodal molecular weight distribution.

This is likely due to the aggregation of polyaniline in the $\mathrm{NMP}$ and $\mathrm{CDCl}_{3}$ or another polar solvant. Such phenomenon maybe resolved by recristalysed solution of ( $\mathrm{PANI}_{-N M P}$ or PANI-CDCl $\mathrm{C}_{3}$ ) in the methanol for 5 hours at $25^{\circ} \mathrm{C}$ or adding $\mathrm{LiCI}$ to the $\mathrm{NMP}$ or $\mathrm{CDCl}_{3}$ solution[26].

Understanding these dramatic effects requires insight into chain growth kinetics and evolution of polymer molecular weight as a function of the experimentals conditions such as reaction time, amount of monomer, solvant and amount of catalyst. While there are several reports on the molecular weight of different form of polyaniline(PANI-ES ,PANI-EB and PANI-HCl ) using gel permeation chromatography [27].

\subsection{Viscosity measurements}

Viscosity measurements were carried out with an Ubbelhode Capillary Viscosimeter (viscologic TI1, version 3-1 Semantec). Intrinsic viscosity [ $\eta$, was measured at $30{ }^{\circ} \mathrm{C}$ in benzene. Viscosity-average molecular weight $\mathrm{Mv}$ was 
calculated according to the equation:

$[\eta]\left(\mathrm{mg} . \mathrm{l}^{-1}\right)=\mathrm{K}$ $\left[\mathrm{M}_{\mathrm{v}}\right]^{\mathrm{a}}$. Viscosity of the polymer is slightly higher $\left(25.79 \mathrm{ml} \mathrm{g-}^{1}\right)$ than that of PANI (19 ml g- $\left.{ }^{1}\right)$ obtained in aqueous solution for $24 \mathrm{~h}$ [28]. Viscosity intrinsic and properties physics of PANI are showed in Table 3.

Table 5: Show properties viscosemitrics of PANI-ES

\begin{tabular}{|l|l|l|l|l|l|}
\hline Concentration & $\mathrm{C}[0]$ & $2 \mathrm{C} / 3$ & $\mathrm{C} / 2$ & $\mathrm{C} / 3$ & $\mathrm{C} / 4$ \\
\hline Moyenne & 3.60 & 3.60 & 3.60 & 3.60 & 3.59 \\
Cinéma .(cst) & 0.61 & 0.60 & 0.60 & 0.60 & 0.60 \\
Dynamics (cp) & 0.90 & 0.90 & 0.90 & 0.89 & 0.89 \\
Relative & 1.01 & 1.00 & 1.01 & 1.00 & 1.00 \\
Spécific & 0.01 & 0.00 & 0.01 & 0.00 & 0.00 \\
Réduite & 12.20 & 13.98 & 19.46 & 20.95 & 22.43 \\
Inhérente & 12.13 & 13.91 & 19.46 & 20.95 & 22.43 \\
Salomon & 12.15 & 13.93 & 19.49 & 20.97 & 22.45 \\
\cline { 2 - 6 } Intr .(g.ml' & $25.1)$ & \multicolumn{5}{|l|}{25.76} & 25.78 \\
\hline
\end{tabular}

\subsection{Proposed process for synthesis of different form of polyaniline catalyzed by Maghnite- $\mathrm{H}^{+}$}

Polyaniline is a conducting polymer with a complex chemistry involving both electron and proton exchange .A distinctive feature of polyaniline among the conducting polymers is that its conductivity is not only controlled by the degree of chain oxidation or number of repetitive units but also by the level of protonation. In Scheme $\mathbf{1}$ are shown the different form of polyanilne in its most stable form at acidic medium ( $\mathrm{pH}=1$ to $\mathrm{pH}=6$ ).
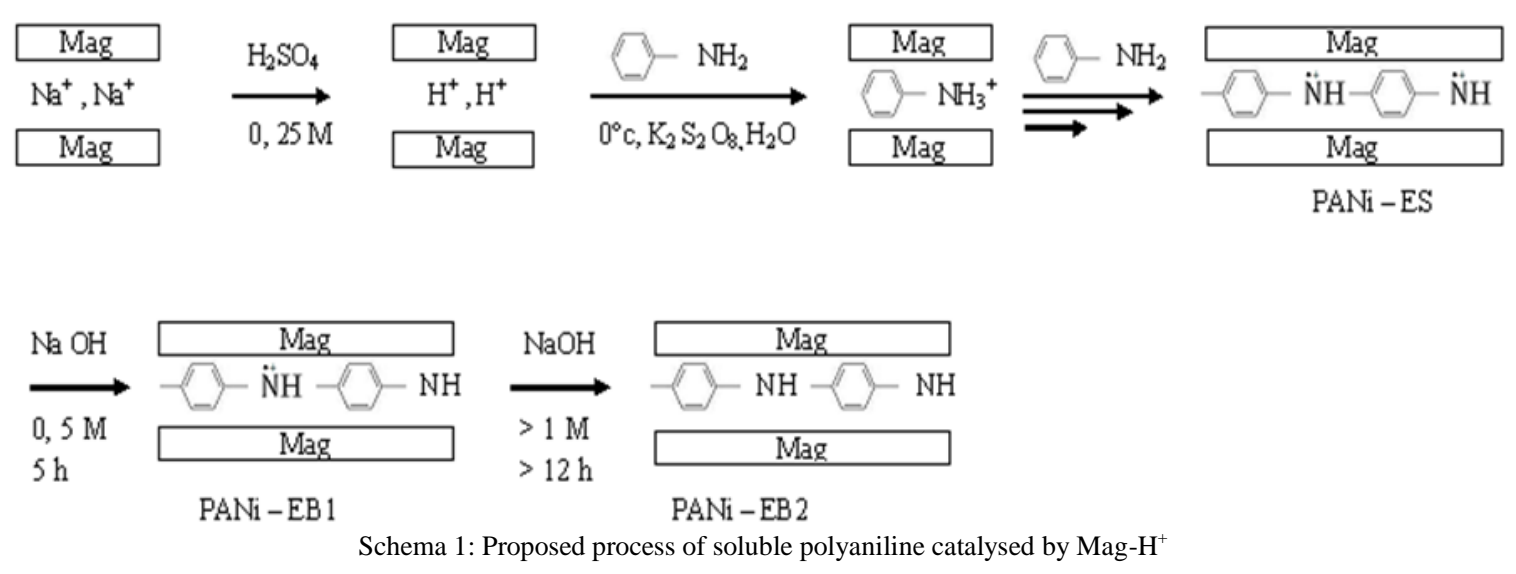

\section{Conclusion}

This study reveals that:

1. Aniline (ANI) can be polymerized in presence of Maghnite- $\mathrm{H}^{+}$an ecocatalyst layered (Algerian montmorillonite).

2. (PANI-Maghnite) materials have been successfully prepared for the heterogeneous polymerization of aniline.

3. The content of polyaniline in (PANI-Maghnite) hybrid nanocomposite product is high $(\sim 84.81 \%)$.

The purpose of this study was to attempt to find an experimental approach for determining selected intrinsic properties of the conducting polyaniline, in its emeraldine oxidation state. It was found that optimization of solubility, molecular weight, conductivity, Could be approached by specific chemical procedures.

Different form of polyaniline (PANI-ES, PANI-EB and PANI-HCl) exhibited a bimodal gel permeation chromatographic (GPC), understanding these dramatic effects requires insight into chain growth kinetics and evolution of polymer molecular weight as a function of the experimentals conditions. 


\section{References}

[1] Ballantine J. A, Davies M, and Purnell H, J. Chem. Soc. Chem. Commun., 427 (1981).

[2] Trivedi DC and Dhawan SK, Chapter 3, in Frontiers of Polymer Research, ed. by Prasad PN and Nigam JK. Plenum Press, New York, p. 419 (1992).

[3] Zeng Q. H, Wang D. Z, Yu A. B, and Lu G.Q., "Synthesis of polymer-montmorillonite nanocomposites by in situ intercalative polymerization" Nanotechnology, vol. 13,pp. 549-553, Aug.2002.

[4] Feng B., Su Y., Song J., and Kong K., "Electropolymerization of polyaniline/MMT nanocomposite ” J. Mater. Sci. Lett., vol. 20, pp. 293-294, 2001.

[5] Mahesh D.B, Basavaraja S, Balaji D.S., Shivkumar V, Arunkumar, and A.Venkataraman L, "Preparation and characterization of Pani and Pani-Ag nanocomposites via interfacial polymerization”, Polymer Composites Vol. 30, Issue 11, pp. 1668-1677, November 2009.

[6] Zeng OH, Yu AB, Lu GQ(Max). Paul DR. "Clay-Based Polymer Nanocomposites: Research and Commercial Development." .J. Nanosci Nanoteclmol.S (1) 1574-1592 (2005)

[7] Ray S, Okamoto M, "Polymer/Layered Silicate Nanocomposites: A Review from Preparation to Processing." Prog. Polym. Sci.. 28 (11) 15391641 (2003).

[8] Ke YC, Strove P, Polymer Layered Silicate, Silica Nanocomposites. Elsevier. Amsterdam (2005).

[9] Lagaly G. "From Clay Mineral-Polymer Interactions to Clay Mineral-Polymer Nanocomposites." Appl. Clay Sci, 15 (1-2) 1-9(1999).

[10] Vadivel A. Synthesis- and Characterization of Organo-Inorganic Conductive Polymer Based Nanocomposites for Electrochemical Power Sources. University of Pune, Pune (2004).

[11] Ruiz-Hilzky E, Meerbeeck AV. "Polymer-Clay Nanocomposites."' In: Bergaya. F, Theng, BKG. Lagaly, G (eds.) Handbook of Clay Science, pp. 583-623. Elsevier. Dordrecht (2006).

[12] Olad A, Rashidzadeh A, "Preparation and anticorrosive properties of PANI/Na-MMT and PANI/OMMT nanocomposites", Progress in Organic Coatings,62 (2008) 293.

[13] G. M. Nascimento, M. L. A. Temperini, "Structure of polyaniline formed in different inorganic porous materials: A spectroscopic study", European Polymer Journal, 44 (2008) 3501.

[14] Belbachir M. and Bensaoula A., US Patent 066969.0101 (2001)

[15] Bae WJ, Jo WH, Park YH, Preparation of polystyrene/polyaniline blends by in situ Polymerization technique and their morphology and electrical property, Synth Met, 132,239-244, (2003).

[16] Belbachir, M, Bensaoula A, Composition and method for catalysis using bentonites, US patent, No7, 094-823 B2,( 2006).

[17] Zhang W, Li Y, Wei L, Fang Y (2003) Mater Lett 57:3366.

[18] Rahmouni A,Harrane A,Belbachir M. 1H-NMR Spectra of Conductive, Anticorrosive and Soluble Polyaniline Exchanged by an Eco-Catalyst Layered (Maghnite-H+),wod journal of chemistry. 8 (1): pp 20-26, 2013.

[19] Rahmouni A,Harrane A,Belbachir M. Maghnite-H+, an eco-catalyst layered (Algerian Montmorillonite) for synthesis of polyaniline/Maghnite clay nano-composites. International Journal of Chemistry and Material Science. Vol. 1(6), pp. 175-181, June 2013.

[20] Cao Y, Smith P, Heeger AJ. Counter-ion induced processibility of conducting polyaniline and of conducting blends of polyaniline in bulk polymers. Synth Met. 1992, 48:91-97.

[21] Subramaniam, Kaiser C K, Gilberd A B,, Wessing PW, J Polym Sci Part B:Polym Phys (1993), $31,1425$.

[22] Bae WJ, Jo WH, Park YH, Preparation of polystyrene/polyaniline blends by in situ polymerization technique and their morphology and electrical property, Synth Met, 132, 239-244, (2003).

[23] N. Bicak, J. Mol. Liq. 116 (2005) 15.

[24] Rao PS, Sathyanarayana DN, Jeevananda T. In Advanced Functional Molecules and Polymers, H. S. Nalwa (ed.), Gordon and Breach, Tokyo, 2001, 3:79.

[25] Athawale AA, Kulkarni MV, Chabukswar VV. Studies on chemically synthesized soluble acrylic acid doped polyaniline, Mat Chem Phys. 2002, 73:106-110

[26] Feng B, Su Y., Song J and K. Kong, "Electropolymerization of polyaniline/MMT nanocomposite ” J. Mater. Sci. Lett., vol. 20, pp. 293-294, 2001 .

[27] Salavagione HJ, Acevedo DA, Miras MC, Motheo AJ, Barbero CA. J Polym Sci Part A: Polym Chem (2004);42:5587.

[28] Rahmouni A,Harrane A,Belbachir M. Thermally Stable Forms of Pure Polyaniline Catalyzed By An Acid-exchanged MMT Clay Called Maghnite-H+ As An Effective Catalyst. Volume 2012 (2012), Article ID 846710, 7 pages doi:10.1155/2012/846710 